\title{
SUERTE DE LA LITERATURA DE VIAJES EN LAS LETRAS CATALANAS: DE JOHN DE MANDEVILLE A JOANOT MARTORELL
}

JUAN MIGUEL RIBERA LLOPIS

Universidad Complutense de Madrid

La confederación catalano-aragonesa vive lo que podríamos denominar cultura medieval del viaje en un doble nivel. En primer lugar, experimentalmente. Desde que Jaume I el Conqueridor rebasara la geografía continental tomando Mallorca (1229), Pere el Cerimoniós (1314-1387) sistematizara la relación con Italia y Alfons V el Magnànim (h. 1396-1458) instalara el trono de la confederación en Nápoles, el Mediterráneo occidental no es sino una plataforma desde la que se proyecta la presencia catalano-aragonesa en el Mediterráneo oriental y el norte de Africa, y desde donde, llevados por un doble aliento comercial y expedicionario, se vislumbra el salto a geografías más lejanas. La presencia en el Mediterráneo oriental, en el Imperio Griego como puerta abierta hacia el mundo turco, contaba ya con una tradición y una infraestructura. Las que habían logrado la Companyia Catalana (1303-1460) y las que documentan los comtats o colonias catalanas como Atenas, Salonica, Neopatria y Tebas. Es el mundo por el que nos llevan no pocos capítulos de la Crònica (h. 1325) de Ramon Muntaner (1265-1336). Esa realidad, tejida sobre el entramado de un marcado activismo comercial como refleja la abundante documentación cancilleresca, razona el que se plantearan empresas que perseguían nuevos y aún más desconocidos destinos. De Etiopía a China, el rastro de en ocasiones perdidas expediciones nos certifica el nivel 
empírico mediante el que el mundo catalano-aragonés vive el impulso medieval del viaje. El reconocimiento coetáneo a la producción cartográfica de focos propios como el de la escuela judía de Mallorca incidiría en lo fehaciente de ese referido nivel.

Pero, además y en segundo lugar, el espectro catalano-aragonés vive la fascinación medieval y demuestra su avidez por la descripción de lejanas geografías. Es en función de esto por lo que el mundo medieval genera toda una serie de productos y vías de información referentes a la materia viajera - lo que yo antes me atrevía a topificar como cultura del viaje - que la nación que aquí nos interesa, la confederación catalano-aragonesa, consume ávidamente.

La corte $\longrightarrow$ insisto en que para certificarlo disponemos de muchos diplomas y documentos cancillerescos y privados, transcritos y ordenados en su parte más relevante por A. Rubio i Lluch ${ }^{1}$-, en muchas ocasiones el monarca personalmente, espera la venida de algún anónimo viajero que regresa, tras años de ausencia, de la Tierra del Preste Juan según referencias que le han hecho llegar o se impacienta ante la tardanza de su llegada. Quiere y quieren celebrar con ellos col. loqui o diálogos para que se les relate toda la experiencia vivida y, seguramente, toda la mixtificación preestablecida que, empiezo a pensar, es el punto en el que confluyen emisor y receptor de una forma previamente pactada y que la misma predisposición del mundo medieval a la maravilla justifica y legaliza. A partir de ese momento, la información recibida, guardada celosamente en la memoria o transcrita y archivada, será uno de los tesoros más preciados del patrimonio cultural.

A ese mismo destino deben ir aquellos textos que el mundo medieval, si atendemos a su rápida y general expansión por Occidente, considera como modelos de esa literatura recapituladora de la finalidad y la experiencia del viaje. Esos grandes best-sellers de la época son reclamados por la corte catalana y en ocasiones traducidos. Aún Infante, Joan I pedirá al monarca francés en 1380 una copia del Libro de las maravillas del mundo (1361) de John de Mandeville y poco después a su suegra, la duquesa de Bar, cuando su larga suerte no había sino empezado a correr. Texto que seguramente mandó traducir al aragonés sin que el traductor pudiera evitar los préstamos del catalán y el reflejo del francés original, y del que se sabe de otra traducción posterior al catalán, atestiguada hacia 1410 y en 1484. De otro de esos clásicos, del texto de Oderico de Porde-

1 Véase mi primera aproximación a ese material en: J. M. RIBERA LLOPIS, Configuración del concepto de «viaje* (Documentos y diplomas catalanes. Siglo XIV), Revista de Filología Románica, U. C. M., n. 7, 1990, pp. 301-308. 
none, de 1330, disponemos de una versión catalana resumida, conservada en la Biblioteca de Catalunya, así como igualmente documentado el interés por lograr una copia. También está traducido al catalán el texto de Aitó de Gorigós, anterior a 1308, con el título de La flor de les històries d'Orient, del siglo XIV. Y sobre todo, debe destacarse la versión catalana de los viajes de Marco Polo, de la segunda mitad del trescientos, amén de la carta del Preste Juan documentada en 1380.

El triple conocimiento que todo lo resumido hasta ahora implica -empirismo viajero, fascinación por la materia viajera y conocimiento de los tempranos clásicos de la literatura de viajes-, debe justificarnos el que, en lengua catalana, esperemos encontrar generada una producción propia en tal sentido y confluyente con la pan-románica. A la hora de establecer la ordenación y la revisión de ese material, me he permitido una triple ordenación de la que aquí daré sucintos ejemplos:

- Hipotéticos libros de viajes.

- Retazos de libros de viajes.

- Libros de viajes.

\section{HiPOTETICOS «Libros DE ViAJES»}

Parto de la base de noticias sobre determinados viajes que, llevados a cabo o no, conociendo la calidad del viajero o por información paralela, deberían habernos hecho esperar un magnífico documento que no se escribió o no se conservó.

Este es el caso del propio Jaume I el Conqueridor de quien conocemos su inclinación y dotes para la narración si pensamos en su colaboración en su propia crónica o Libre dels Feyts y que en dos ocasiones intentó viajar a Tierra Santa: de haber alcanzado esa meta, logico es que hubiera hecho una relación de su itinerario y sabrosa si pensamos en su capacidad como narrador.

Tampoco hay noticia sobre el viaje de fra Jeroni de Catalunya a China, a Tartaria, entre 1318 y 1323, ni escrito ni dictado. Ni tampoco de las diferentes expediciones a la Tierra del Preste Juan, una vez que se le ubicó en Abisinia, aunque -en la promovida por Alfons V, en 1428 - la cancillería redactó un memorial, diciendo a los expedicionarios el tipo de información que debían recoger y documentar, contenido que lo convierte en un verdadero índice de un libro de viajes. 


\section{RETAZOS DE «LIBROS DE VIAJES»}

Me refiero en este caso a fragmentos textuales que, cumpliendo con la materia y la retórica del libro de viajes, se incluyen en otro texto de intenciones más complejas. Ramon Llull (h. 1232-h. 1315), en el largo periplo de su biografía, rozó las fronteras del mundo conocido y debió recoger todo tipo de información sobre lejanas geografías que, llegado el momento y como hizo con los más variados componentes, utilizó funcionalmente en la composición de sus obras. Este es el caso del capítulo LXXXVIII del Libre de Evast e Blanquerna (h. 1283-1295) donde, transmitiendo la información traída por los misacges o mensajeros, se nos dan diversas informaciones, entre ellas sobre Sudán, cruzando el dato antropológico y costumbrista con el componente mágico, recurso constante en la retórica de la información viajera medieval.

3. «LIBROS DE VIAJES»

Aunque parezca sorprendente, la dinámica expansionista y expedicionaria catalano-aragonesa no se ha traducido en la documentación de muchos libros de viajes resueltos plenamente. $\mathrm{Al}$ menos recuperados y puestos al alcance del lector y del crítico. Una estancia en Barcelona y en el Arxiu de la Corona d'Aragó, gracias a la ayuda concedida por el Programa d'Estudis Catalans Joan Maragall (Caixa de Barcelona / Fundación Ortega y Gasset), la he ocupado en el rastreo de posibles noticias de nuevos textos. De lo que disponemos es de libros de viajes, del subgénero libro de peregrinacion - itinerario. Uno de génesis muy particular, en la que no nos vamos a detener aquí, y que conduce hasta Irlanda, al llamado Purgatorio de San Patricio. Es el texto de finales de siglo XIV de Ramon de Perellós (s. XIV-h. 1419) y que, desde Aviñón, pasa por París y diversos lugares de Inglaterra, hasta llegar a su destino e incluyendo también el regreso. Otro, de 1323, es un itinerario a Tierra Santa, relatado por Joan Rovira de Montblanch y que, de Cataluña, pasa rápidamente a Egipto y desde aquí traza un circular viaje a los Santos Lugares, para volver a la patria de origen. Todo ello con oficiales móviles políticos en su planteamiento. 
No voy a entrar, sin embargo, en la descripción de estos textos, labor que he ido haciendo en otras aportaciones a nuestro proyecto de investigación sobre los libros de viajes ${ }^{2}$. Tal vez haya otra manera, aquí y ahora, de hacer más amena la demostración de hasta qué punto las letras catalanas viven esa constante pan-románica. Con esa intención, me desviaré hacia otro destino y otros textos. A lo largo de mi colaboración en dicho proyecto me ha ido interesando cómo se va formulando una escritura que transmita al receptor la noción y" descripción del espacio visitado por el emisor, y, a su vez, qué suerte retórica corren esos espacios en las diferentes formas de escritura con que cuenta la genealogía medieval. Para entendernos y siempre dentro del campo catalán, cómo aparecen Atenas y Constantinopla, por ejemplo, en un diploma cancilleresco, una crónica, un -hipotético - libro de viajes o, finalmente, en una novela: cómo, en último grado, al llevarlo al terreno de la ficción, el espacio real transferido retóricamente se convierte en una realidad autónoma. El arco que va de uno al otro texto que aquí tenemos traza una pirueta que, ralentizada en sus fases, nos debe permitir el descubrir el destino que los lugares comunes de la escritura medieval del viaje hallan, al menos, en las letras catalanas. Detengámonos, ahora pues, en esta otra singladura.

El Libro de las maravillas del mundo de John de Mandeville se nos ofrece, desde su texto, como obra de un inglés que salió de su patria en 1322 y que, regresado en 1356 o 1357, pasó a redactarla, reordenando la experiencia de sus viajes y con la única finalidad de distraerse. Sólo la erudición filológica ha venido después a poner en tela de juicio tanto la mixtificación que puede haber detrás de esa autoría como el juego intertextual que propicia la realidad resultante. No entraremos ni en lo uno ni en lo otro. Por el contrario, si atendemos a uno de los episodios -el que después reaparecerá en la novela caballeresca catalana Tirant lo Blanc (1490) de Joanot Martorell y tal vez revisada por Martí Joan de Galba-, podemos reconocer rasgos de su retórica y, tal vez, el porqué de la elección posterior de ese episodio. Es el de la hija de «Hipocrás», que no es otro que el médico Hipócrates, encantada en forma de dragón.

2 Proyecto de investigación sobre los libros de viajes en el mundo románico, dirigido por la Dra. Eugenia Popeanga (Dpto. de Filología Románica, U.C.M.). Entre las aportaciones del proyecto citaré la publicación del volumen Los libros de viajes en el mundo románico (anejo I de la Revista de Filología Románica, U.C.M., 1991) y las actas del I Coloquio Nacional sobre los Libros de Viajes en el Mundo Románico (Revista de Filología Románica, U.C.M., n. $\left.{ }^{\circ} 8,1991\right)$. En lo concerniente al estudio de documentación catalana, contienen respectivamente mis dos colaboraciones Hacia una escritura del «viaje»: en torno a documentos catalanes de los siglos XIII-XV y Viajeros catalanes a Ultratumba. 
John de Mandeville, partido del norte europeo, y cerrado el bloque de su supuesta experiencia viajera en el Imperio Griego, advierte cuál será la ruta para quien quiera llegar a Jerusalén, pasando por territorio turco y dando noticias de todo tipo. Así se arriba a «... la isla de Lango» (p. 40 ${ }^{3}$, perteneciente a "Hipocrás» y cuya hija «... está (...) en manera de un gran dragón» (p. 40). Ese presente -que, ciertamente, lo «dicen»- conecta con una estancia del viajero igualmente en presente. Hay en ello un riesgo o compromiso por parte del autor que él elude con rapidez añadiendo - ya en pretérito- que así se lo «... decían muchas personas que la habían visto» y que «... yo por lo poco que allí estuve no la pude ver» (p. 40). El autor se escuda tanto en su breve estancia como en que al fin y al cabo no la vio. Pero no dice si cree o no en esa mutación y tampoco renuncia a narrar la leyenda que trasladará al receptor a aquella lejana geografía. Automáticamente vuelve al presente de indicativo para introducir el relato de la historia de la desdichada dama desde la perspectiva de quienes, al parecer, sí la han visto. $\mathrm{O}$ al menos creen firmemente en su triste destino.

A partir de ahí se relata el argumento de un encantamiento causado por «Diana» y que necesita de una prueba de amor para devolver por siempre a la dama a su estado natural. El relato resistiría bravamente el esquema de funciones propuesto por V. Propp para el estudio del cuento popular y al final, podríamos aventurar, se nos ofrecería como una variante ancestral del tema que se resolverá prioritariamente bajo la formulación de La bella durmiente. Aquí, un doble protagonismo masculino $-\mathrm{y}$ otros tantos si atendemos al «... y después ningún caballero la ha visto que no muera» (p. 41)- fracasará en su empresa. No le interesa a Mandeville que la tragedia haya sido solventada. La presencia acechante del dragón, aunque él no nos mienta diciendo que lo vio, dota de un aspecto maravilloso a la geografía por la que él pasa y a su propio paso por ella. Por eso incide en presente de indicativo cruzado con el pretérito en que se relatará la leyenda - y que a su vez se cruza con los presentes verbales del diálogo insertado-, que «... está en una cava de un castillo fuerte antiguo, y se demuestra dos y tres veces en el año, la cual no hace mal a ninguno si no le hacen a

3 Las citas del texto de Mandeville las daré de acuerdo con la edición de la versión aragonesa preparada por P. LIRIA MONTAÑES, Libro de las maravillas del mundo de Juan de Mandevilla (Zaragoza, Caja de Ahorros de Zaragoza, Aragón y Rioja, 1979), indicando directamente la página. La correspondencia de esa versión con el texto francés del que partirian tanto aquélla como la versión catalana notificada - y es lógico pensar que a una de las tres debió acogerse el autor de Tirant lo Blanc- puede efectuarse acudiendo a la transcripción del original que da M. de Riquer en el Excurs VIII de Aproximacio al «Tirant lo Blanc» (Barcelona, Quaderns Crema, 1990, pp. 302-306). 
ella» (p. 40). Verbos y constancia temporal constatan la presencia del elemento maravilloso en el espacio visitado por el viajero. Espacio, de esta manera, mixto en su naturaleza - a la presencia empírica del viajero se le añade la constatación maravillosa de los naturales del país, en los que deberíamos creer-, al que se ha podido acceder desde una geografía cartográficamente constatable en la época y del que se podrá pasar a la isla de Rodas que, tal y como la «... tienen e gobiernan los hospitaleros de San Juan» (p. 41), se muestra como espacio cristiano. Nada opone esos mundos. Si así fuera, en cualquier caso, el autor no hace otra cosa que relatar las creencias del país visitado. No se ha comprometido con ello. Pero ciertamente y de cara al receptor su paso por aquella isla no ha sido vano. Y su escritura ganó con ello.

No debe sorprendernos la reaparición de ese texto y esa leyenda en la novela catalana Tirant lo Blanc tal y como en su día ya quedó demostrado ${ }^{4}$. Es esta novela texto que también juega intertextualmente con títulos de autores precedentes, ya fueran nacionales - Guillem de Torroella, Bernat Metge, Joan Roís de Corella... - o extranjeros - Giovanni Boccaccio, Dante Alighieri...- La popularidad del texto debido a Mandeville - trescientos manuscritos conservados, la existencia entre ellos de las referidas traducciones en el ámbito catalano-aragonés, el consumo popular del texto que viene a significar de acuerdo con P. Liria Montañés ${ }^{5}$ la cantidad de copias poco lujosas- facilita además la comprensión de que ese fuera uno de los títulos con los que se permitió trabajar el novelista. En todo caso, el porqué debería dirigirse a la elección de ese episodio. Alguno de los elementos antes destacados puede ayudarnos a entenderlo. Otros pueden surgir ahora. Y en cualquier caso habrá que destacar cómo el préstamo no evita la reelaboración con otros fines.

Lango está, constatablemente, en la ruta que, siguiendo a «Tirant», ha de seguir «Espèrcius». Eso sí, en dirección inversa a la de Mandeville, ahora hacia Constantinopla. Y, además, junto a Rodas, que es uno de los puntos esenciales en la geografía caballeresca de la novela y conocido por el receptor catalán por los hechos allí acontecidos y trasladados a la ficción. Me refiero al sitio sufrido por Rodas en 1444 y en el que figuró población catalana. La mala fortuna lleva a «Espèrcius» a Lango - donde, de su escasa población, la mayoría eran

4 Véanse al respecto las referencias dadas a partir del descubrimiento del plagio por W. J. Entwistle (1922), por M. de Riquer en su texto anteriormente citado (vid. nota 3) así como en El «voyage de Sir John Mandeville en català» (Miscellània d'homenatge a E. Moreu-Rey, Montserrat, Abadia, 1988, III, pp. 151-162).

${ }^{5}$ P. LIRIA MONTAÑEs, introducción a Libro de las maravillas del mundo de Juan de Mandevilla, ed. cit., p. 18. 
«... exelats de l'illa de Rodes» (p. 1043) — que rápidamente se presenta como que «... aquella illa era encantada e deguna cosa no hi podia profitar» (p. 1043). Desde aquí, el narrador no hace otra cosa que intercalar incrementos narrativos que si bien amplían el ropaje dramático de la acción, no son sino formas dilatorias - suspense narrativo- hasta que se conozca cuál es el tipo de encantamiento, cómo «Espèrcius» se verá implicado en él y cómo se resolverá.

La necesidad de comer y la piedad del pastor -incremento de orden fisiológico, de presencia común en la novela - retrasará el relato de este último en el que hay que buscar la más exacta traslación del episodio de Mandeville. Con un cambio. Como el que aquí narra es un natural de la isla, alguien que debe haber visto al dragón-dama en alguna de sus periódicas apariciones, no necesita excusarse en la experiencia de nadie: «... car jo l'he vista moltes vegades» (p. 1044) nos dice $y$, ante la insistencia verificatoria de «Espèrcius» y afirmándose en la experiencia, le contesta:

"- Senyor, no hi poseu dubte negú, car jo us parle ab tota veritat, car tot aço e lo més del que us he recitat és estat en mon temps, e no us volria haver mentit per cosa en lo mon» (p. 1045).

Se insiste, de esta manera, en el presente empírico de los habitantes de la isla de Lango que ya escuchara Mandeville. Y sobre la base de esa verosímil constatación, el narrador inserta otro incremento narrativo - ahora de orden caballeresco- a partir del impulso que lleva a «Espèrcius» a querer «... experimentar aquesta ventura» (p. 1045) y a llevar a buen puerto el desencantamiento de la dama que no se lograra en el material legendario más primitivo. «Espèrcius» recorre un repertorio de lugares comunes en la retórica de la aventura del caballero: el camino hacia la aventura — $\ll$... feu la via del castell...»-, la purificación ante el Señor - «... pregà a la immensa bondat de Nostre Senyor»- y encomendamiento a Dios - «... e comanà's a Déu»-, la entrada en el lugar mágico - «... entrà dins la cova tant com la claror li durà...»- $y$ requerimiento de la prueba - «... llançá un gran crit perquè lo drac l'oís» (p. 1046)—. Ese proceso podría ser aplicable al que cumplieron los caballeros del texto de Mandeville, sólo que allí no se asiste a una relación tan pormenorizada. Pero el acierto narrativo de Joanot Martorell, el segundo de plenitud narrativa, no está tanto en ese

${ }^{6}$ Las citas de Tirant lo Blanc las daré, indicando directamente la página, por: JoAnOt Martorell, Marti JoAn De Galba, Tirant lo Blanc, ed. de M. de Riquer, Barcelona, Ariel, 1979. 
topificado incremento como en la pausa -el silencio y la congelación narrativa- que se crea en torno al caballero de ojos cerrados ante la fealdad del monstruo, el beso del dragón que requiere su propio desencantamiento y la presencia y la voz de la ya bella doncella (p. 1046). Más allá del gran acierto de ese momento - que por su tono nos hace pensar que el desarrollo del episodio ha de deberse a Martorell-, el narrador vuelve a la utilización de los incrementos narrativos, fisiológico en primer lugar, cortés después, mediante el doble panegírico puesto en boca de los nuevos enamorados, caballeresco finalmente mediante el reconocimiento de la aventura por parte de los compañeros de «Espèrcius» $y$ la acción de gracias - «E feren llaors e gràcies a la divina Clemència...» (p. 1049)-

Pero más allá incluso de ese no por esperado menos deleitable happy end hay otra cuestión a destacar. El de la operación efectuada sobre la información del espacio mágico - verosímilmente mágico- que a su manera era la isla de Lango en el texto de Mandeville. Piénsese que la isla que visita la novela catalana más de dos siglos después es una isla desierta frente a la que conociera Mandeville, bastante poblada pues «... allí me decían muchas personas que la habían visto (a la dama-dragón)...» (p. 40); y que sus únicos pobladores a la llegada de «Espèrcius» eran un «pastor» $y$ «quatre casats» expulsados de Rodas. El espacio habitable y acogedor de Mandeville se ha convertido, en Martorell, en espacio punitivo. Autor tocado de un cierto afán de verosimilitud, intenta razonar la sobrevivencia de sus personajes en la isla. Para Mandeville, los naturales han aprendido a vivir con su monstruo; para Martorell los náufragos reciben cuidados de unos y otros que atienden sus cuerpos. Pero mientras el primer viajero pasa por Lango y cuenta esa leyenda de la misma manera en que pocas líneas antes ha dicho que de Mirrea destacaría sus buenos vinos, «... muy fuertes, que se llaman vinos marques» (p. 40), el narrador del segundo viaje necesita quedarse con la leyenda para ensalzar irónicamente el protagonismo de su caballero.

Adelantado el cuatrocientos, la orden de caballería está dejando de ser la filosofía y la ideología -el código- de fondo de todo un sistema. Empieza a operarse con él de una forma escapista. Llevándolo abiertamente a la categoría de lo fantasmagórico, más allá de lo maravilloso -pensemos en un Amadís de Gaula (1492) - o intentando dotarlo de una cierta lógica realista. Aunque Joanot Martorell es de los que opta prioritariamente por esta vertiente - pensemos ahora en sus caballeros reclamando comida o necesitando ser atendidos en su salud, y ya no en si éste es uno de los posibles episodios intercalados por Galba-, en ocasiones nos sorprende con una actuación más rutinaria aunque, eso sí, históricamente más comprensible. Por eso, de la isla oralmente - a través de la voz de sus habitantes - presentada por Mandeville, el novelista se queda con 
el espacio oracularmente descifrado por el «pastor», lo que propicia la actuación caballeresca de «Espèrcius». Donde, una vez más y de acuerdo con P. Liria Montañés ${ }^{7}$, Mandeville acierta a combinar lo fantástico y lo cotidiano en una resultante verosímil y sobre todo amena, Joanot Martorell —que es uno de los mejores potenciadores medievales de ese afán de verosimilitud- elige en esta ocasión la acentuación de lo maravilloso entre un paréntesis de razonamientos fisiológicos. Lo que le permitirá crear ese momento de plenitud literaria al que antes me refería, el que contiene la pirueta grotesca del beso invertido, sólo posible en un espacio plenamente autónomo y que él, sólo él, devolverá a la más poblada y humana realidad una vez utilizado:

\begin{abstract}
«Aprés, per temps, vingueren aquí fustes, les quals noliejaren e feren venir gent d'altres parts per poblar l'illa, la qual en breu temps fon molt be poblada; e edificaren aquí una ciutat molt noble, qui Espertina fou nomenada, la venturosa. E molts altres llocs, viles e castells hi foren edificats e poblats. E moltes esglésies e cases de religiosos...” (p. 1049).
\end{abstract}

Si ha necesitado por unos momentos vaciar la isla de Lango de los habitantes que le contaron la leyenda de la hija de «Hipocrás» a Mandeville para quedarse sólo con la leyenda y su caballero, todo fue en aras de la ficción. Cumplida ésta, puede regresar la sociedad y sus signos, desde los comerciales a los espirituales. Que esa, de nuevo, fue tal vez la isla que visionara Mandeville. Más de dos siglos después, no obstante, la capacidad de ficción ya es capaz de modular los espacios necesarios en función de sus necesidades o sus caprichos. Y eso sin romper los nexos. Porque si de John de Mandeville y su texto se ha podido afirmar ${ }^{8}$ que, una vez demostrada la falsedad de su viaje, ha dejado de ser un buen cronista de viajes para ser un mejor autor literario, fue ya en este último en quien Joanot Martorell encontró magnificamente narrado un episodio que poder llevar con plena autonomía a su geografía ya, desde un primer momento, literaria. Claro está que si ésta fue aquí su suerte - la de convertirse en repertorio de futuras aventuras narrativas- no hay que olvidar que viajeros más experimentados como Cristobal Colón partieron de criterios innovadores existentes en el texto de John de Mandeville como es su referencia a la redondez de la tierra.

7 P. LiRIa Montañes, op. cit., p. 18.

8 Ibidem, p. 17. 